\title{
The design and construction of a power quality parameters recorder
}

\author{
M.Rogó $\dot{z}^{1,2}$, marek@agh.edu.pl Z.Hanzelka ${ }^{2}$ hanzel@agh.edu.pl \\ ${ }^{1}$ ENION SA Power Distribution Company - Cracow, Poland \\ ${ }^{2}$ University of Science and Technology AGH - UST, Cracow, POLAND
}

\begin{abstract}
Summary
The paper presents the authors' approach to design and construction of power quality parameters recorder conforming the requirements of IEC 61000-4-30 standard. The recorder was designed and built according to the measurement algorithms developed by the authors. These algorithms meet the requirements of IEC 61000-430, IEC 61000-4-15 and IEC 61000-4-7 standards. Modeling of the applied algorithms and analysis of their sensitivity to variation in some parameters were carried out in a Matlab-Simulink environment. Algorithms for measuring modules were subjected to comprehensive tests verifying their correctness. Also, the tests required by relevant standards or proposed by international organizations, e.g. CIGRE [7], and additional test developed by the authors, were carried out.
\end{abstract}

Keywords: power quality, measurement, design, construction

\section{Introduction}

This paper presents a power quality parameters recorder designed on Matlab-dSpace platform, which is based on the international standards: IEC 61000-4-7, 61000-4-15 and 61000-4-30, that give a functional and design specification for measuring apparatus intended to indicate and assess quality of electric power supply. The paper is organized as follow. First an overview on modeling investigation is presented. Then the description of the analyzer structure is described and finally the simulation and practical tests and obtained results are discussed with conclusion.

\section{Modeling invistigations}

The objective of the modeling investigation was to reconstruct the measuring procedure in such a manner that the relevant requirements of standardization documents were met [8-10]. The algorithms were designed to independently fulfill requirements for each parameter and provide simultaneous functioning of all other modules. The modeling investigation was carried out in Matlab-Simulink environment which ensures very good representation of mathematical models as well as good credibility and repeatability of results. Algorithms of all measuring modules were subjected to tests verifying their accuracy.

The structure of the analyzer's hardware version is presented in further sections and information on a given measuring module structure or relevant publications, which provide its detailed description, are referred to. Consideration was also given to imprecise formulations contained in the above-mentioned standards which allow for some liberal interpretation regarding the instrument design and construction. The methods of results presentation - aggregation, smoothing, percentiles, tables, etc., were assessed, or publications describing the proposed methods proposed in standards $[9,10]$ and other standardization documents $[12,13,14]$, were referred to. The models of measuring modules are the basis for developing the hardware version of the power quality analyzer. Implementations were made using the rapid prototyping environment dSPACE and DS1104 board. Voltage transducers LEM CV 3-500 of very high accuracy, with $0-300 \mathrm{kHz}$ bandwidth, were used as both the interface and isolating element.

The models were tested using test signals generated in the modeling environment, and the physical modules were tested using a reference instrument. The practical measurements have been performed in LV network of one university building.

\section{The analyzer structure}

Except of the harmonics analyzer module, where synchronous sampling was abandoned due to the hardware constraints, all modules are compliant with the developed models.

The measuring board management and readout of a part of measurement data is achieved from the ControlDesk level - an experiment management package. Code generation, programming the board and data readout are made from the Matlab level. The analyzer block diagram is shown in Fig. 1.

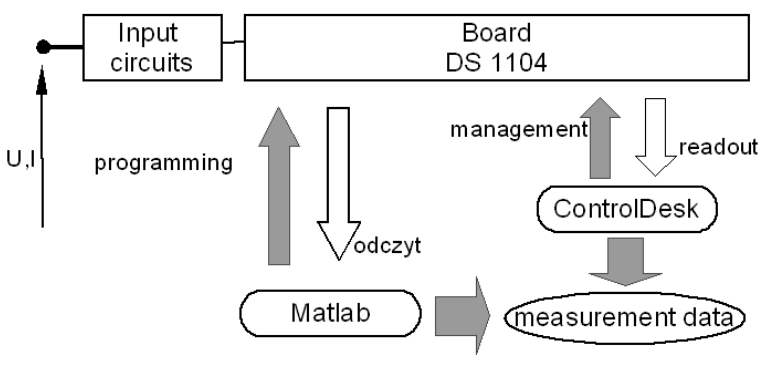

Fig. 1 Block diagram of the analyzer

Figure 1 shows both the hardware part: the input circuits of DS1104 board with analogue-digital converters and execution processor, and the concepts of programming, management and data acquisition from the board. The readout of measuring data is made from the ControlDesk 
and from the Matlab level. This way of readout results from different characters of measurement data, i.e. the data obtained in specified time intervals ( $\mathrm{rms}$ voltage value, flicker severity) and data of a random nature (voltage dips, swells).

Power quality indices can be classified into four categories in terms of the frequency of data recording:

- $200 \mathrm{~ms}$ aggregated values, subject to further time aggregation, e.g. rms voltage value, unbalance factor, harmonics, interharmonics,

- 10-minute short term flicker severity $\mathrm{P}_{\text {st }}$ values, used for evaluating the $\mathrm{P}_{\mathrm{lt}}$ index,

- frequency values recorded every 10 seconds,

- parameters recorded only at the time of their occurrence - of voltage dips, swells, supply interruptions.

Recording of measurement data has been organized taking into consideration the above classification, its block diagram is shown in Fig. 2.

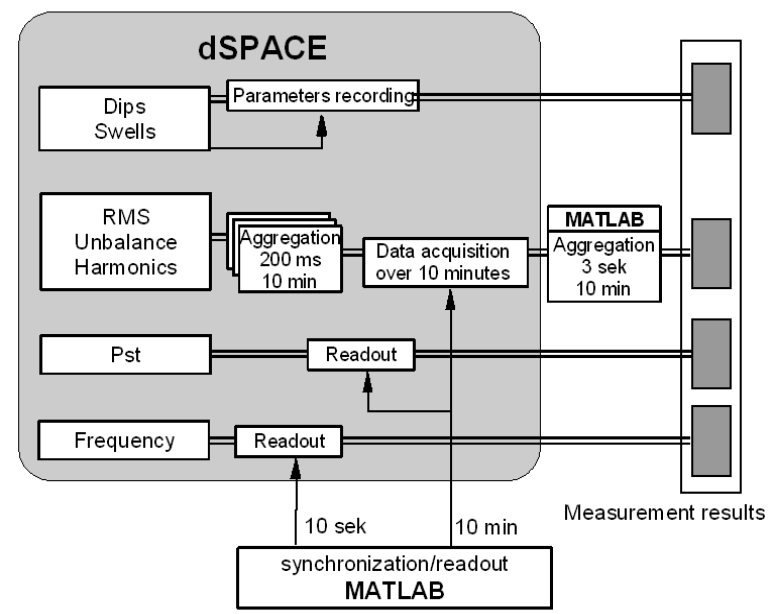

Fig. 2 Block diagram of readout and recording of the measured values

The measurement results must be timestamped with clock time whose uncertainty shall not exceed $\pm 20 \mathrm{~ms}$ (the requirement of standard [10]). As the measurement board does not support timestamping the acquired data with clock time, measurement data acquisition is performed from the level of an external application, in this case - MATLAB. In the Matlab environment a system clock of PC computer is used to timestamping the measurement results. Considering the low accuracy of PC clocks in Windows environment, the system time is synchronized with a reference clock. The synchronization is made in two ways: (i) via the Internet, using the Network Time Protocol (NTP); (ii) by means of GPS receiver. This solution may be used where Internet is inaccessible. This solution has not been applied.

In the first step the results of measurement of rms voltage value, unbalance factor, harmonic and interharmonic levels are aggregated in $200 \mathrm{~ms}$ time interval. The aggregation result is refreshed every ca. $1 \mathrm{~ms}$; depending on the sampling frequency $(10 \mathrm{kHz}$ or $10240 \mathrm{~Hz})$ it may give $1 \mathrm{~ms}$ or $0.97 \mathrm{~ms}$. The data acquisition block is timetriggered from Matlab every 10 minutes because the acquisition triggering is synchronized with the clock time. The "acquisition" block reads data packets from the "200 ms aggregation" block and stores them. A subsequent triggering ends the acquisition of the preceding 10-minute block of results, which is written to file, so the single file contains $200 \mathrm{~ms}$ aggregated values. Further time aggregation, i.e. 3-second, 10-minute, 2hour, of these results is run outside the dSpace environment. Where only 10-minute aggregated values have significance for the user, the possibility of aggregation in the dSpace environment has been foreseen. The synchronized readout every 10 minutes is executed from the Matlab environment.

The short term flicker severity $P_{s t}$ is evaluated in the dSpace environment. The current value of $P_{s t}$ is computed every $20 \mathrm{~ms}$. The record of $\mathrm{P}_{\mathrm{st}}$ value every 10 minutes is synchronized from Matlab. The long term flicker severity $\mathrm{P}_{1 t}$ is computed from 12 successive $\mathrm{P}_{\mathrm{st}}$ values outside the dSpace environment.

Recording of the occurrence of a voltage dip/swell and its parameters is internally triggered in the dSpace environment. Each event generates a file in which parameters of this event are recorded. in the dSpace environment the time of start and end of a voltage $\mathrm{dip} / \mathrm{swell}$ is recorded in the environment's relative time counted from the start of application. In order to "locate" the event on the clock time axis, the clock time of recording the file to disk is used.

The frequency value is recorded every 10 seconds; record triggering and time synchronization with the clock time is executed by Matlab.

\section{Voltage rms value}

A possibility of determining the rms voltage value on the basis on its definition and with the use of a low-pass FIR filter, operated in the $5-100 \mathrm{~Hz}$ band with Kaiser smoothing window, was taken into consideration during developing the model, whose construction specifics are given in[10]. Research has shown that the use of the filter has no negative influence on the measurement result Fig. 3, but in the same time significantly reduces the number or arithmetical calculation. It should, however, be noted that the presented results apply to the $5-100 \mathrm{~Hz}$ filter. The filter used for measuring rms voltage value in a wider band, up to $2 \mathrm{kHz}$, is of much larger complexity, whereas the accuracy of measurement is lower. Therefore, for practical reasons, the rms voltage value is determined from definition.

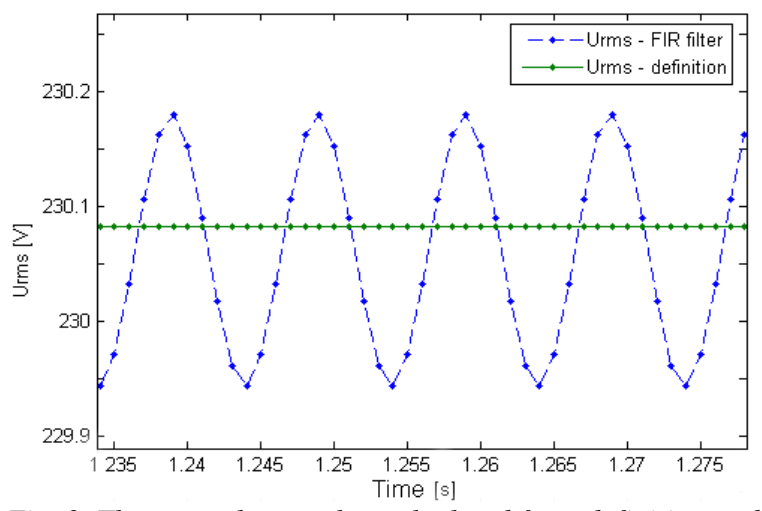

Fig. 3. The rms voltage value calculated from definition and evaluated by means of FIR filter

The full-cycle rms voltage value is calculated with the sampling frequency whereas it value in the basic 10-cycle measurement window is calculated according to rel. (1). 


$$
U_{r m s, 0.2}=\sqrt{\frac{\sum_{i=1}^{N} u_{r m s}^{2}(i)}{N}}
$$

where:

$u_{r m s,(i)}$ - i-th instantaneous sample of rms voltage value

$N$ - number of rms voltage samples aggregated in time interval $200 \mathrm{~ms}$. The number of samples $N$ depends on the sampling frequency.

The measurement accuracy and linearity of the rms voltage measuring module was experimentally verified over the range from 2.3 to $300 \mathrm{Vrms}$. The maximum error did not exceed $0.03 \%$ - see table 1 .

Table 1 Accuracy of the voltage rms value measurement

\begin{tabular}{|l|l|l|}
\hline dSpace & Topas & Error [\%] \\
\hline 2.31 & 2.31 & 0.001 \\
\hline 4.63 & 4.61 & 0.007 \\
\hline 11.48 & 11.47 & 0.001 \\
\hline 22.96 & 22.94 & 0.007 \\
\hline 57.48 & 57.46 & 0.007 \\
\hline 114.94 & 114.92 & 0.007 \\
\hline 172.42 & 172.4 & 0.007 \\
\hline 229.91 & 229.91 & 0 \\
\hline 249.87 & 249.86 & 0.003 \\
\hline 287.41 & 287.41 & 0.023 \\
\hline 299.92 & 299.99 & 0.023 \\
\hline
\end{tabular}

The example of one-week voltage variation recorded by the developed recorder and the reference instrument Topas is presented in Fig. 4, Fig. 5 shows histogram of voltage differences in phase voltages.

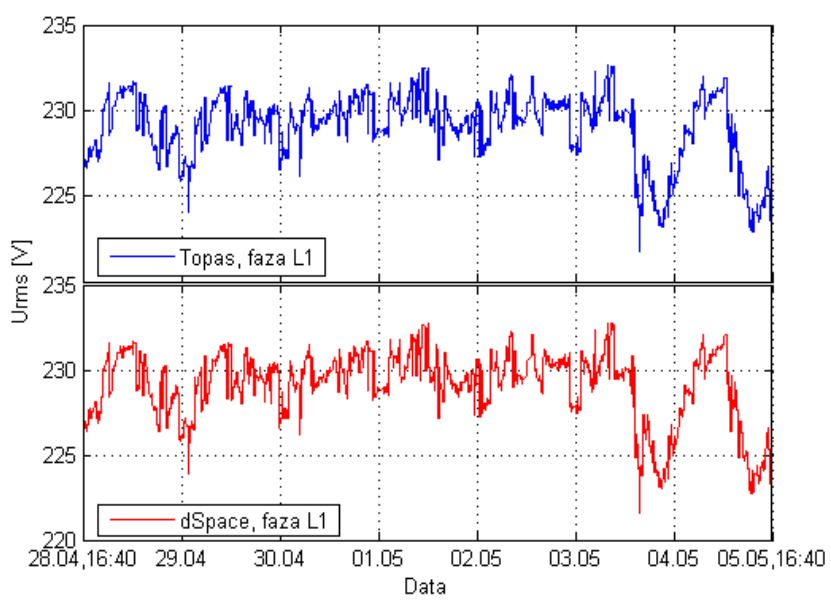

Fig. 4 An example daily graph of rms voltage value

Table 2 summarizes statistical parameters, based on 10minute aggregated values, characterizing the voltage value in phase L1 determined using both analyzers.

Table 2 Statistical parameters of the voltage rms measurement
\begin{tabular}{|l|l|l|l|}
\hline & Topas & dSpace & Error \\
\hline Min & 221.81 & 221.62 & 0.063 \\
\hline Mean & 229.73 & 229.87 & 0.047 \\
\hline Max & 234.36 & 234.35 & 0.003 \\
\hline CP05 & 225.55 & 225.55 & 0 \\
\hline CP50 & 230.02 & 230.19 & 0.057 \\
\hline CP95 & 232.59 & 232.71 & 0.04 \\
\hline CP99 & 233.45 & 233.46 & 0.003 \\
\hline
\end{tabular}

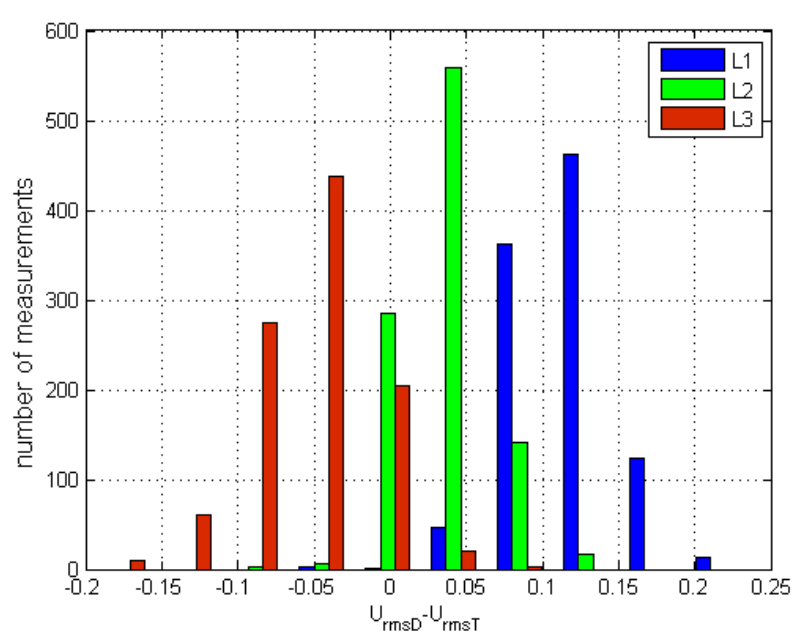

Fig. 5 Histogram of voltage differences in phase voltages.

The obtained results demonstrate very high accuracy of the rms voltage measurement. The distribution of differences (Fig. 5) confirms the random nature of errors.

\section{Voltage unbalance}

Usually, as a measure of voltage unbalance is taken coefficient $K$ expressed by the ratio of negative sequence component or/and zero sequence component to the voltage or current fundamental component. In practical application is much easer to determine the voltage unbalance factor from rms voltages. Standard [10] provides relation (2) for evaluating the unbalance factor using 10-cycle rms line-to-neutral voltages.

$$
\begin{aligned}
K_{2 U}=\sqrt{\frac{1-\sqrt{3-6 \beta}}{1+\sqrt{3-6 \beta}} \cdot 100 \%} \\
\beta=\frac{U_{A B}^{4}+U_{B C}^{4}+U_{C A}^{4}}{\left(U_{A B}^{2}+U_{B C}^{2}+U_{C A}^{2}\right)^{2}}
\end{aligned}
$$

The developed model employs also an alternative method, proposed in [15], which consists in determining the unbalance factor using the maximum deviation from the mean value of rms line-to-line voltage values (3). Averaging period is $200 \mathrm{~ms}$.

$$
K_{2 U}=\frac{\Delta U_{\max }\left(U_{A B}, U_{B C}, U_{C A}\right)}{U_{s r}} \cdot 100 \%
$$

where:

- $U_{\max } U_{A B}, U_{B C}, U_{C A)}$ - maximum deviation of any of the three line-to-line voltages from the mean value,

- $U_{s r}$ - the mean value of three line-to-line voltages,

Table 3 shows the voltage unbalance factor values calculated according to the above three relations. The investigation was carried out for several sets of voltages. Both the voltage magnitude and phase displacements between the voltages were varied. 
Table 3 The voltage unbalance factor values for different measurement methods

\begin{tabular}{|c|c|c|c|c|c|c|}
\hline & $\begin{array}{c}\mathrm{U}_{\mathrm{B}} \\
{[\mathrm{Urms}]} \\
{[\mathrm{deg}]}\end{array}$ & $\begin{array}{c}\mathrm{U}_{\mathrm{B}} \\
{[\mathrm{Urms}]} \\
{[\mathrm{deg}]}\end{array}$ & $\begin{array}{c}\mathrm{U}_{\mathrm{C}} \\
{[\mathrm{Urms}]} \\
{[\mathrm{deg}]}\end{array}$ & $\begin{array}{c}\mathrm{K}_{2 \mathrm{U}} \\
\text { def. }\end{array}$ & $\begin{array}{c}\mathrm{K}_{2 \mathrm{U}} \\
\text { rel. } \\
(2)\end{array}$ & $\begin{array}{c}\mathrm{K}_{2 \mathrm{U}} \\
\text { rel. } \\
(3)\end{array}$ \\
\hline 1 & $167.9 \angle 0^{\circ}$ & $184 \angle-120^{\circ}$ & $200.1 \angle 120^{\circ}$ & 5.05 & 5.05 & 4.403 \\
\hline 2 & $349.6 \angle 0^{\circ}$ & $322 \angle-120^{\circ}$ & $294.4 \angle 120^{\circ}$ & 4.949 & 4.95 & 4.312 \\
\hline 3 & $232 \angle 0^{\circ}$ & $240 \angle-121^{\circ}$ & $242 \angle 119^{\circ}$ & 1.306 & 1.31 & 1.26 \\
\hline 4 & $230 \angle 0^{\circ}$ & $230 \angle-119^{\circ}$ & $230 \angle 121^{\circ}$ & 0.582 & 0.58 & 0.505 \\
\hline 5 & $230 \angle 0^{\circ}$ & $231 \angle-120^{\circ}$ & $229 \angle 120^{\circ}$ & 0.251 & 0.25 & 0.217 \\
\hline 6 & $230 \angle 0^{\circ}$ & $230 \angle-115^{\circ}$ & $230 \angle 125^{\circ}$ & 2.91 & 2.91 & 2.55 \\
\hline
\end{tabular}

Taking the values evaluated according to the unbalance factor definition as a reference, the values calculated from the relation (1) given in standard [10] are practically the same. The relation (1) is analytically identical with the definition thus the observed errors are numerical ones. The unbalance factor values computed from relation (2) contain an error of ca. 13\%. the exception is No.3 set of voltages, where error is $3.5 \%$. Considering the above results, the relation (1), proposed in standard [10], is employed for hardware implementation. It ensures a very high level of accuracy of the voltage unbalance factor representation, provided the accuracy of evaluation of rms line-to-line voltages is satisfactory.

Figure 6 shows daily variation of the unbalance coefficient measured by means of both the Topas instrument and dSpice, table 4 summarizes statistical parameters over a one week period.

Table 4 Statistical parameters of the voltage unbalance measurement

\begin{tabular}{|c|c|c|c|}
\hline & Topas & dSpace & Error \\
\hline Min & 1.28 & 1.37 & 6.96 \\
\hline Mean & 1.62 & 1.72 & 6.11 \\
\hline Max & 1.88 & 2.02 & 7.43 \\
\hline CP05 & 1.46 & 1.61 & 8.41 \\
\hline CP50 & 1.63 & 1.71 & 4.95 \\
\hline CP95 & 1.72 & 1.83 & 6.81 \\
\hline CP99 & 1.78 & 1.93 & 8.67 \\
\hline
\end{tabular}

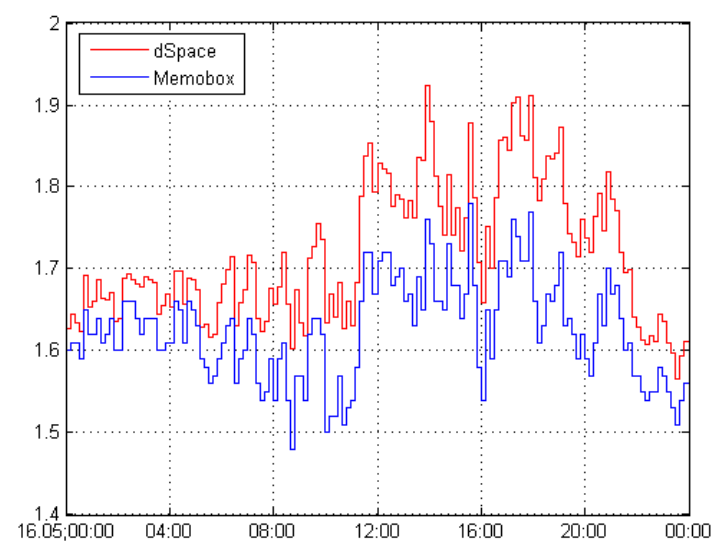

Fig. 6 Example of daily variation of the unbalance coefficient

\section{Voltage distortion}

The harmonics analysis module, was developed according to the requirements of standards [9] and [10], its block diagram is shown in Figure 7. Spectral analysis employs the fast Fourier transform (FFT) technique. The model was subjected to a number of tests which confirmed its correct operation and good accuracy of analysis under conditions of heavily distorted input signal, as well as fundamental component frequency fluctuations. Testing and assessment of grouping and smoothing were also carried out, as proposed in standard [9].The details of the model construction, performed tests and detailed analyses are presented in [16].

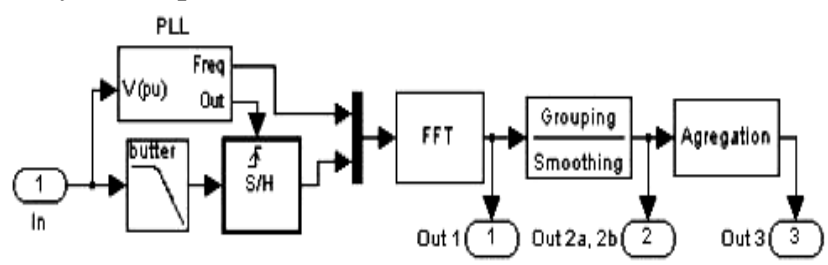

Fig. 7 Block diagram of the harmonics analysis module

Taking into account the requirements regarding synchronous sampling and considering a number of construction options, the following parameters were selected:

- sampling frequency: $f_{a}=10 \mathrm{kHz}$,

- number of samples in the measuring window: $N=2000$,

- measuring window width: $T_{m}=0,2$ sek.

It should be emphasized that sampling frequency of the analysis block (and therefore of all other blocks) was selected because of the necessity for rms voltage measurement to be updated every $10 \mathrm{~ms}\left(\mathrm{U}_{\mathrm{rms} 1 / 2}\right)$. This time-interval governs the detection of events, i.e. voltage dips, swells and supply interruptions. The selection of $10 \mathrm{kHz}$ sampling frequency, while at the same time standard [9] requires the $0.2 \mathrm{sec}$ measuring window, precludes the use of radix-2 algorithms, which would significantly accelerate the execution of FFT analysis. Alteration of sampling frequency gives the number of samples 10240 , ensuring $2^{\mathrm{n}}$ samples in the measurement window as required for the radix-2 algorithms, results in evaluation of $\mathrm{U}_{\mathrm{rms} 1 / 2}$ value every ca. $9.7 \mathrm{~ms}$ instead of $10 \mathrm{~ms}$.

It has been found that the use of smoothing window, e.g. the Hanning window recommended in standard [9], reduces the spectrum blur but does not eliminate it, hence the synchronous sampling was needed. From several synchronization options, the PLL synchronization was chosen. This method has several advantages, like selectivity (capability of synchronization to the fundamental component or its multiple, also in the presence of heavy distortion) and robustness against disturbances and variation in the input signal amplitude. It, of course, is not free from disadvantages - some constructional difficulties and variability of the output signal, even in the input steady state conditions. The block diagram of the applied phase-locked loop is shown in Fig. 8. 


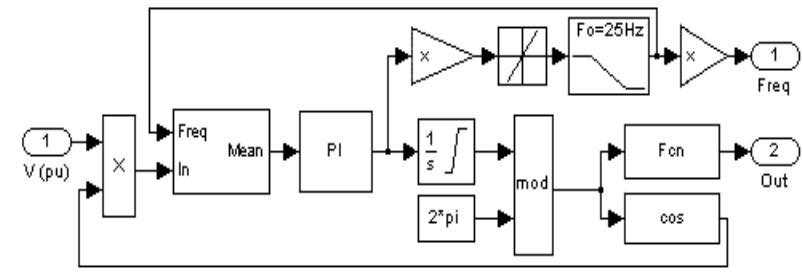

Fig. 8 The phase-locked loop (PLL) block diagram

Figure 9 shows the daily graph of THD, table 5 summarizes statistical parameters of THD measurement.

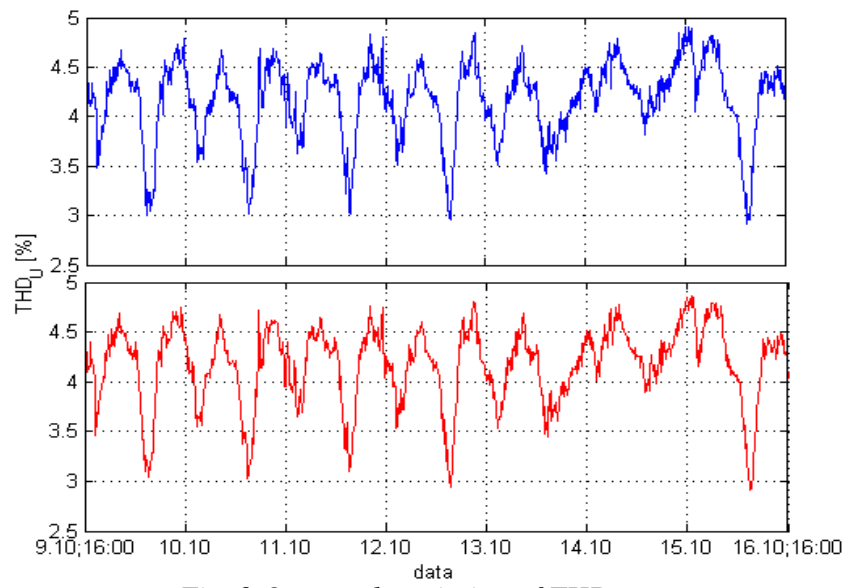

Fig. 9 One-week variation of THD

Table 5 Statistical parameters of THD measurement

\begin{tabular}{|c|c|c|c|}
\hline & Topas & dSpace & Error \\
\hline Min & 2.909 & 2.906 & 0.003 \\
\hline Mean & 4.172 & 4.172 & 0 \\
\hline Max & 4.907 & 4.857 & 0.05 \\
\hline CP05 & 3.33 & 3.333 & 0.003 \\
\hline CP50 & 4.25 & 4.257 & 0.006 \\
\hline CP95 & 4.689 & 4.673 & 0.016 \\
\hline CP99 & 4.812 & 4.795 & 0.017 \\
\hline
\end{tabular}

\section{Flickermeter}

The model has been developed according to recommendations of standard IEC 61000-4-15, which specifies the principles of flickermeter structure, provides its block diagram and specification for each block. The block diagram of the described model is shown in Figure 10.

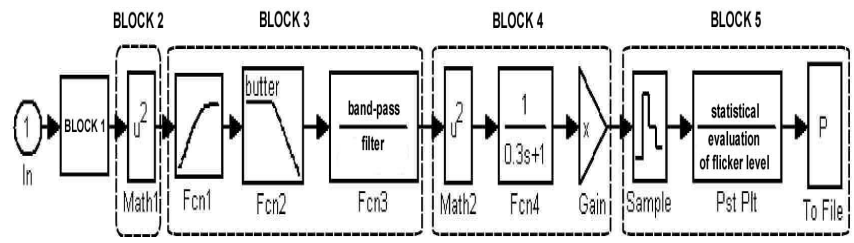

Fig. 10. Block diagram of the described flickermeter model

The detailed description of the model construction an testing is contained in publications [2,3,4,5]. Analysis of the model sensitivity to changes of selected filters parameters has been performed. Such investigation enables to check the model overall reaction to changes in parameters of a chosen filter. It enables to realize how stringent are the requirements of standard [8] concerning filters parameters. Each time the parameter of only filter has been changed and the test 1 , i.e. checking the response to square-wave signal modulation, according to the table 1 of the standard [8] was performed. Figures 11 to 13 show the tests results of alterations in filters parameters for: $0.05 \mathrm{~Hz}$ high-pass filter, $35 \mathrm{~Hz}$ low-pass filter and sliding mean filter with $300 \mathrm{~ms}$ time constant.

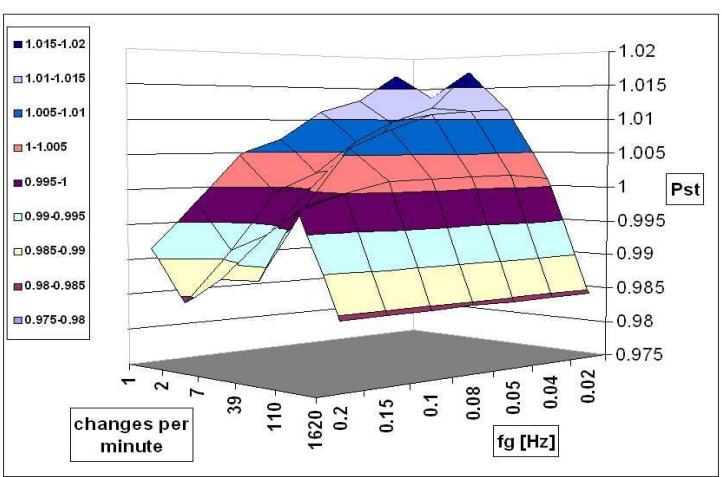

Fig. 11. Sensitivity of the model readings to the change in the high-pass filter cut-off frequency $0.05 \mathrm{~Hz}$ [ [fig.10]

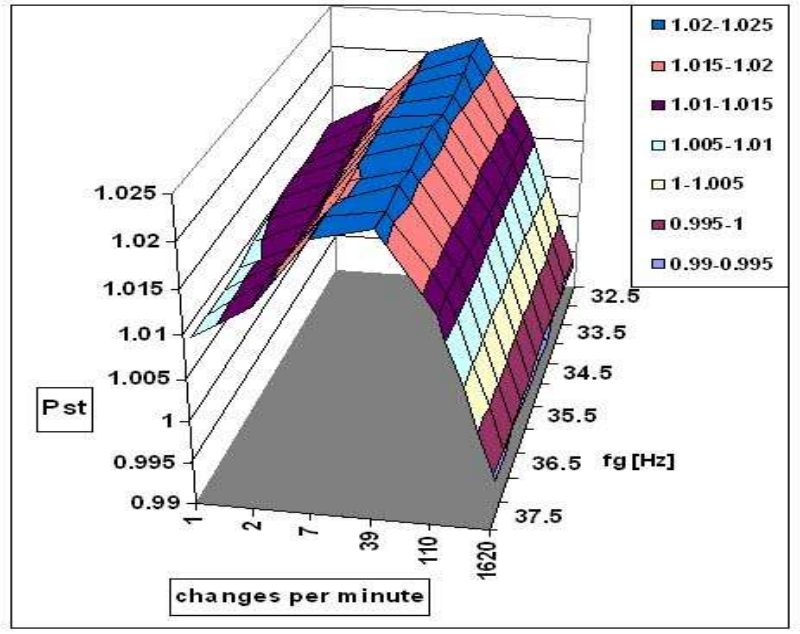

Fig. 12. Sensitivity of the model readings to the change in the low-pass filter cut-off frequency $35 \mathrm{~Hz}$ [fig.10]

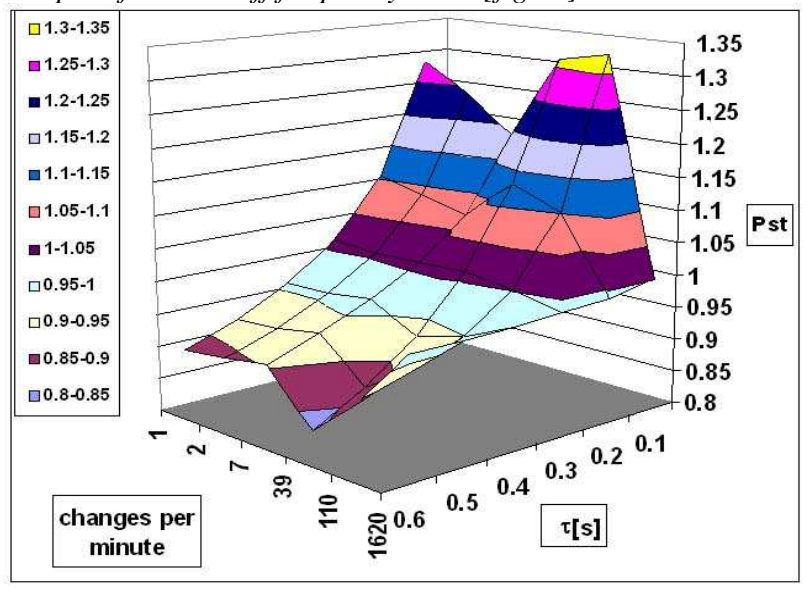

Fig. 13 Sensitivity of the model readings to change in the time constant $300 \mathrm{~ms}$. of the sliding mean filter [fig.10]

As can be seen from the presented results, the flickermeter developed model is not susceptible to alternation of the $0.05 \mathrm{~Hz}$ high-pass filter and $35 \mathrm{~Hz}$ low- 
pass filter parameters. it is, however, highly sensitive to changes in the $300 \mathrm{~ms}$ sliding mean filter parameters. Within the range the time constant variation from 100 to $600 \mathrm{~ms}$. The model has met the accuracy requirements only for the filter with $300 \mathrm{~ms}$ time constant.

Considering the test for flickermeter response to the input voltage phase jump, proposed by the CCU2/UIE Working Group on Power Quality [7], a detailed modeling investigation, described in [5], were carried out. The investigation has confirmed the flickermeter's sensitivity to this type of disturbance. The results were experimentally confirmed using the Topas recorder. The response of both the flickermeter model and Topas recorder to a constant phase jump in the measured voltage $\left(-35^{\circ}\right)$ vs. the angle at which the disturbance occurs, is shown in Figure 14.

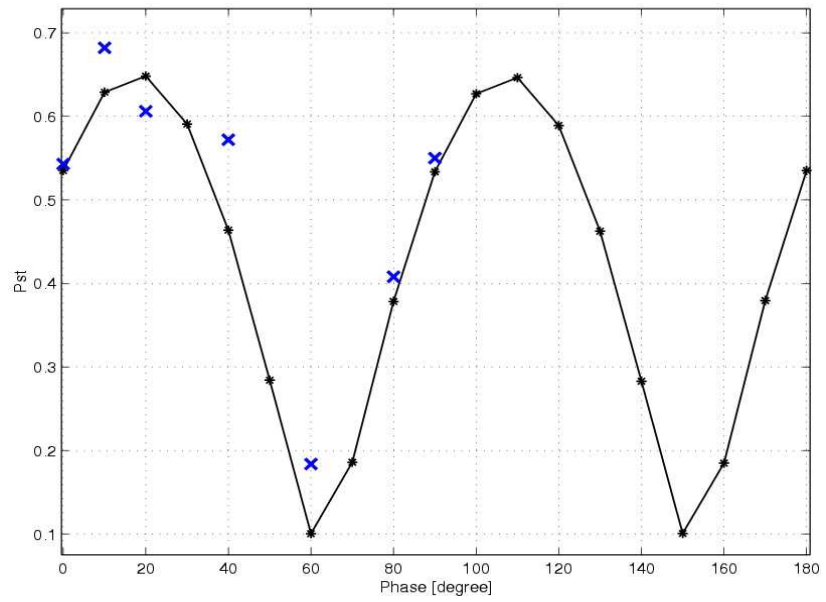

Fig. 14 Change in $P_{s t}$ as a function of the angle at which the disturbance occurred (phase jump: $-35^{\circ}$ ); $\times$ - the experiment [5]

The measuring module, developed on the basis of the flickermeter model, was subjected to test required by standard [8]. For given input signal parameters the result should be $1 \pm 5 \%$. The signal parameters and results are listed in table 6 .

Table 6 The results of test 1 for voltage fluctuations measurement (according to the table 5 in [8])

\begin{tabular}{|c|c|c|}
\hline $\begin{array}{c}\text { Number of } \\
\text { changes per } \\
\text { minute }\end{array}$ & $\begin{array}{c}\text { Voltage } \\
\text { change } \\
\text { dV/V [\%] }\end{array}$ & Pst \\
\hline 1 & 2.72 & 0.995 \\
\hline 2 & 2.21 & 1.011 \\
\hline 7 & 1.46 & 1.02 \\
\hline 39 & 0.905 & 0.993 \\
\hline 110 & 0.725 & 1.017 \\
\hline 1620 & 0.402 & 1.027 \\
\hline
\end{tabular}

Additionally, several control test developed on the basis of publication [1], were carried out. The results of tests 2 and 3 , i.e. linearity test for square-wave and sine-wave modulation, are listed in tables 7 and 8.
Table 7 Changes in the modulating voltage and $P_{s t}$ values measured in the linearity test for square-wave modulation [1]

\begin{tabular}{|c|c|c|c|}
\hline $\begin{array}{c}\text { Test } \\
{[1]}\end{array}$ & $\begin{array}{c}\text { Value of } \\
\mathrm{k}\end{array}$ & Pst & Pst/k \\
\hline $2 \mathrm{~A}$ & 1 & 1.017 & 1.017 \\
\hline $2 \mathrm{~A}$ & 10 & 9.658 & 0.965 \\
\hline $2 \mathrm{~A}$ & 20 & 19.713 & 0.985 \\
\hline $2 \mathrm{~B}$ & 0.2 & 0.217 & 1.085 \\
\hline $2 \mathrm{~B}$ & 1 & 1.027 & 1.027 \\
\hline $2 \mathrm{~B}$ & 2 & 2.19 & 1.095 \\
\hline $2 \mathrm{~B}$ & 5 & 5.35 & 1.07 \\
\hline $2 \mathrm{~B}$ & 10 & 10.74 & 1.074 \\
\hline $2 \mathrm{~B}$ & 20 & 21.44 & 1.072 \\
\hline
\end{tabular}

Table 8 Changes in the modulating voltage and Pst values measured in the linearity test for sine-wave modulation

\begin{tabular}{|c|c|c|c|}
\hline $\begin{array}{c}\text { Test } \\
{[1]}\end{array}$ & $\begin{array}{c}\text { Value of } \\
\mathrm{k}\end{array}$ & Pst & Pst/k \\
\hline 3A & 1 & 1.004 & 1.004 \\
\hline 3A & 10 & 10.007 & 1 \\
\hline 3A & 20 & 19.81 & 0.99 \\
\hline 3B & 0.2 & 0.237 & 1.18 \\
\hline 3B & 1 & 1.013 & 1.013 \\
\hline 3B & 2 & 1.983 & 0.99 \\
\hline 3B & 5 & 5.003 & 1 \\
\hline 3B & 10 & 9.97 & 0.997 \\
\hline 3B & 20 & 19.997 & 0.99 \\
\hline
\end{tabular}

Figure 15 shows a one-week variation of short term flicker severity, statistical parameters which characterize the voltage fluctuations measurement are tabulated in table 9.

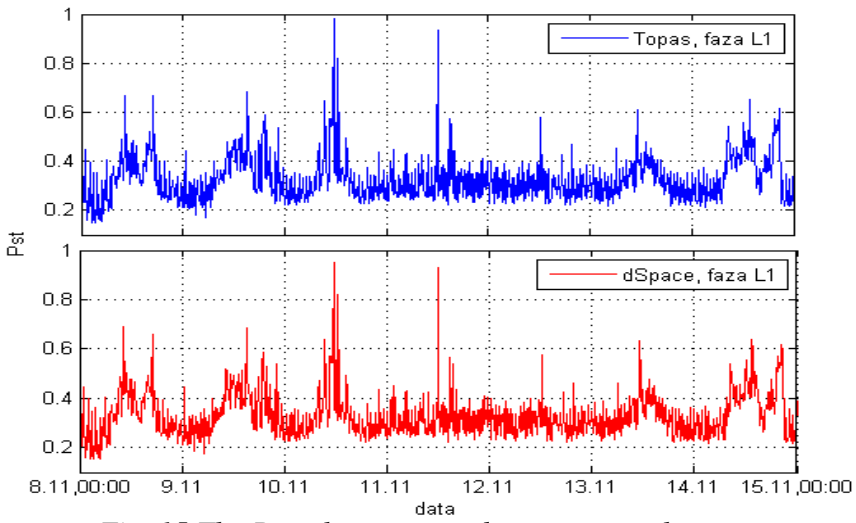

Fig. 15 The $P_{\text {st }}$ value measured over one week

Table 9 Statistical parameters of the voltage fluctuations measurement

\begin{tabular}{|c|c|c|c|}
\hline & Topas & dSpace & Error \\
\hline Min & 0.15 & 0.149 & 0.006 \\
\hline Mean & 0.326 & 0.328 & 0.012 \\
\hline Max & 0.984 & 0.953 & 0.158 \\
\hline CP05 & 0.224 & 0.228 & 0.02 \\
\hline CP50 & 0.309 & 0.313 & 0.02 \\
\hline CP95 & 0.488 & 0.492 & 0.022 \\
\hline CP99 & 0.605 & 0.613 & 0.043 \\
\hline
\end{tabular}

\section{Voltege dips and swells, short supply interruptions - power quality events}

The model of determining power quality events was developed according to the requirements of standard [10]. The model and analysis of methods for evaluation of 
these disturbances, proposed in [10] and other documents [12-14], are extensively described in [6].

\section{Frequency}

Considering the requirements of standard [10] related to frequency measuring, i.e. the measurement over 10second time interval, a classical method of clock pulses counting over the cycle (or half-cycle) of the measured signal [17] was adopted. This is the one of the simplest methods for frequency measuring and allows for good accuracy over long measurement time. The accuracy depends on several factors, namely:

- The clock frequency and accuracy. i.e. on the number of samples in the measurement interval; the higher the reference clocking frequency the more accurate the measurement is. The accuracy can be improved by counting clock pulses over a larger number of cycles/half cycles.

- The accuracy of zero crossing detection.

Accuracy of zero crossing detection depends on both the sampling frequency and the level of distortion of the measured signal. in order to eliminate multiple zerocrossing the input signal should not contain harmonic and/or interharmonic components. The block diagram of the frequency measuring module is shown in figure 16 .

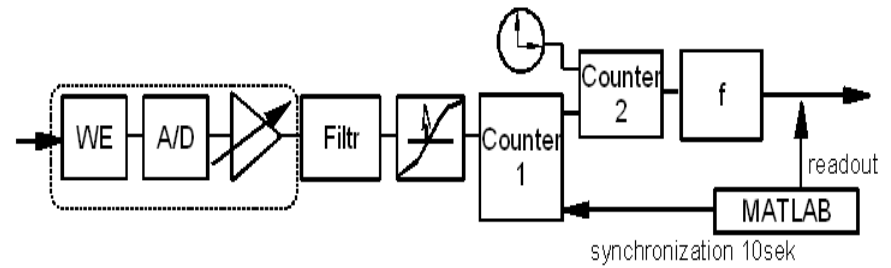

Fig. 16 Block diagram of the frequency measuring module

The frequency measuring module consist of the following function blocks:

- band-pass filter with $30-70 \mathrm{~Hz}$ bandwidth, which filters the harmonic and most of interharmonic components in order to eliminate multiple zero-crossing, see Fig. 17,

— zero-crossing detector,

- counter which counts the fundamental component cycles up to 499 , i.e. in ca. 10 seconds interval,

- counter which counts clock pulses for 499 cycles of the fundamental component,

— frequency computing block,

- the output results latch block.

It should be noted that clock pulses are counted over the interval equal to 499 cycles of the fundamental component, what makes ca. 9.98 seconds. The shortened time of measurement enables synchronization with clock time in 10-second intervals, as required by standard [10]. According to standard [10] the results of frequency measurement do not subject to time-aggregation, nevertheless the 10-minute aggregation is maintained for the purpose of assessment.

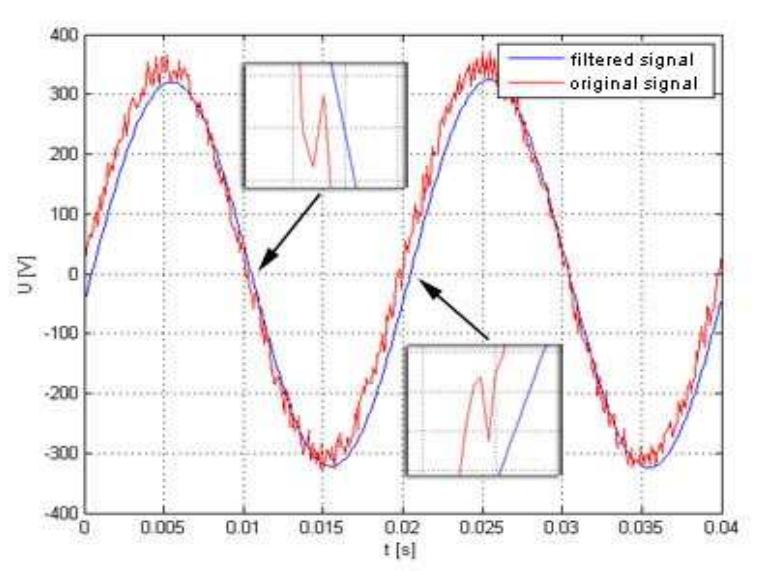

Fig. 17 Signal filtering to eliminate multiple zero-crossing

Figure 18 shows one-week recording of frequency, its statistical parameters are tabulated in table 9.

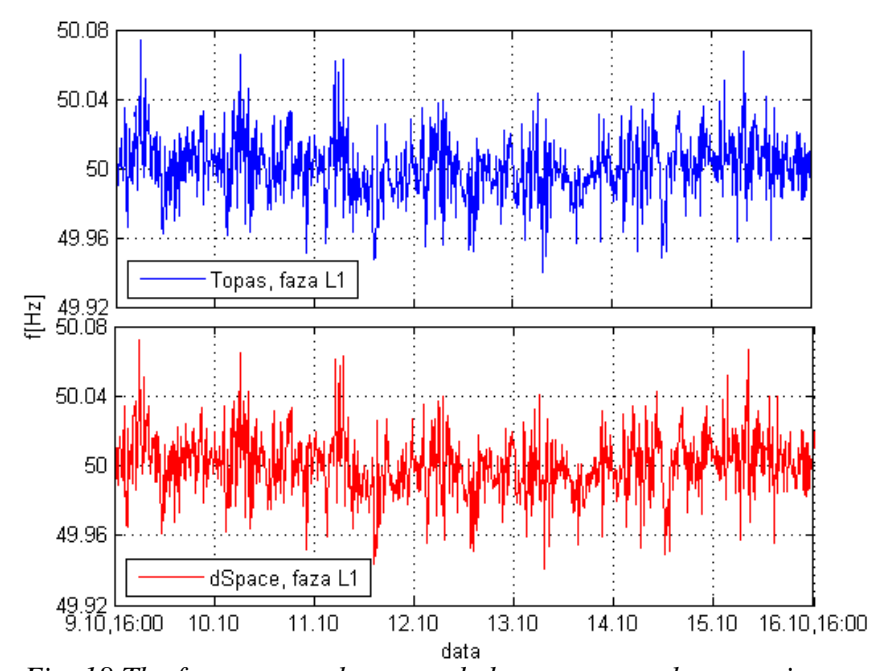

Fig. 18 The frequency value recorded over one-week measuring period

Table 10 The statistical parameters of frequency measurement

\begin{tabular}{|c|c|c|c|}
\hline & Topas & dSpace & Error \\
\hline Min & 49.94 & 49.941 & 0.001 \\
\hline Mean & 50.001 & 50 & 0.001 \\
\hline Max & 50.074 & 50.072 & 0.003 \\
\hline CP05 & 49.973 & 49.972 & 0.002 \\
\hline CP50 & 50.001 & 50.001 & 0.001 \\
\hline CP95 & 50.03 & 50.029 & 0.001 \\
\hline CP99 & 50.043 & 50.042 & 0.001 \\
\hline
\end{tabular}

\section{Conclusions}

In the authors' opinion, the information contained in standards [8-10] can be a guide for the design of power quality analyzer. These standards, however, allow for some liberal interpretation of their provisions what may lead to measurement methods based on different principles.

The developed measurement algorithms were successfully implemented in the hardware version, creating this way the power quality analyzer. Except of one limitation (the lack of synchronous sampling), the analyzer complies with the requirements of standards [810]. laboratory test and then experimental investigation 
confirmed its measurement method is correct and accurate.

\section{Acknowledgement}

The works has been financed by State Committee for Scientific Research within the research project No. 3 T10A 04328

\section{References}

[1] Marcin Szlosek, Zbigniew Hanzelka, Andrzej Bień, Marek Rogóż, Marek Hartman; IEC Flickermeter used in power system monitoring. Part 1: Comparative tests. Electrical Power Quality and Utilisation, Volume 9, No 1, 2003, Cracow, Poland

[2] Marek Rogóż, Andrzej Bień, Zbigniew Hanzelka, Marcin Szlosek, Marek Hartman; IEC Flickermeter used in power system monitoring. Part 2: Investigation of the flickermeter model sensitivity, Electrical Power Quality and Utilisation, Volume 9, No 1, 2003, Cracow, Poland

[3] Rogóż Marek; The IEC flickermeter model Elektrotechnika i Elektronika, AGH-UST, Volume 22, No.1, 2003

[4] Rogóż Marek; Analysis of the flickermeter sensibility model research. Power Quality Exhibition \& Conference, November 4-6, 2003 Long Beach, California, USA

[5] Marek Rogóż, Andrzej Bień, Zbigniew Hanzelka; The influence of a phase change in the measured voltage on flickermeter response, 2004 International Conference on Harmonics and Quality of Power, September 12-15, 2004 "Lake Placid, New York, U.S.A

[6] Marek Rogóż; RMS, unbalance and voltage dips measurements for assessment of electric power quality (in
Polish), International Worshshop, 16-19 Oct. 2004, Wisla (Poland)

[7] IEC flicker meter used in power system voltage monitoring. Draft 8, Test Protocol prepared by CCU2-CIGRE C4.05/CIRED 2/UIE WG2 Joint Working Group on Power Quality, May 2003.

[8 IEC 61000-4-15. Testing and measurement techniques Section 15: Flickermeter - Functional and design specifications 1998 .

[9] IEC 61000-4-7. Testing and measurement techniques General guide on harmonics and interharmonics measurements and instrumentation, for power supply systems and equipment connected thereto, 2002.

[10] IEC 61000-4-30. Testing and measurement techniques Power quality measurement methods, 2003.

[11] Dave Coombes Improving accuracy of power and power quality measurements

[12] P1564.2. Voltage sag indices - draft 2. IEEE, November 2001.

[13] Flaming M. Predicting power quality. Power Transfmission and Distribution, June 2000. p.42.

[14] Desquilbert G, Foucher C, Fauquembergue P. Statistical analysis of voltage dips. 3rd Inter. Conf. On Power Quality: End-Use Applications and Perspectives, Amsterdam, October?? 1994.

[15] ANSI C84.1. American national standard for electric power systems and equipment - voltage ratings, 1995.

[16] Rogóż Marek Model of the harmonic analyzer for the needs of power quality assessment

[17] Wiszniewski A,: Algorithms of digital measurements in power control systems (in Polish)

[19] Szlosek M, Piekarz M, Hanzelka Z, Bien A. Comparative (industrial) tests of flickermeters. XVII International Conference on Electricity Distribution, Barcelona,2003 